\title{
Un pálido reflejo del fascismo: \\ la dictadura de Primo de Rivera en los informes diplomáticos italianos
}

\author{
A Pale Reflection of Fascism: \\ Primo de Rivera's Dictatorship in Italian Diplomatic Reports
}

\author{
Juan Avilés Farré \\ Universidad Nacional de Educación a Distancia (UNED) \\ javiles@geo.uned.es \\ ORCID: 0000-0001-9755-279X
}

Recibido: 23-11-2016

Aceptado: 15-3-2017

Cómo citar este artículo / Citation: AVILÉS FARRÉ, Juan (2017). Un pálido reflejo del fascismo: la dictadura de Primo de Rivera en los informes diplomáticos italianos. Pasado y Memoria. Revista de Historia Contemporánea, 16, pp. 69-90.

https://doi.org/10.14198/PASADO2017.16.04

\section{Resumen}

Este ensayo analiza las informaciones y las valoraciones de los diplomáticos italianos sobre la política interior de España durante el régimen de Primo de Rivera (1923-1930). Sus informes ofrecen interesantes referencias de primera mano sobre el régimen y presentan el interés adicional de ofrecer una comparación con la simultánea experiencia del régimen fascista italiano. Confirman que Primo de Rivera tuvo una persistente tendencia a inspirarse en el modelo fascista, que culminó en el fracasado intento de institucionalizar el régimen en 1929, aunque en opinión de los diplomáticos italianos la dictadura de Primo de Rivera sólo llegó a representar un pálido reflejo del fascismo.

Palabras clave: Dictadura de Primo de Rivera, Diplomacia italiana, Fascismo, España, Siglo XX.

\section{Abstract}

This essay analyses the information on and the assessments of home politics in Spain during the Primo de Rivera regime (1923-1930). Those reports provide interesting 
first-hand accounts on the regime and have the additional value of offering a comparison with the simultaneous experience of the Italian fascist regime. They confirm that Primo de Rivera had a persistent tendency to seek inspiration in the fascist model. This eventually led to the unsuccessful attempt to institutionalize the regime in 1929, although according to the Italian diplomats Primo de Rivera's dictatorship reached no further than a pale reflection of fascism.

Keywords: Primo de Rivera's Dictatorship, Italian Diplomacy, Fascism, Spain, 20 ${ }^{\text {th }}$ Century.

Este ensayo se propone analizar las informaciones y las valoraciones que sobre la política interior del régimen de Primo de Rivera dieron los diplomáticos italianos de la época, incluidos los embajadores Raniero Paulucci di Calboli, que lo fue hasta noviembre de 1927, y Giuseppe Medici, que le sucedió en esa fecha, así como los diversos encargados de negocios que les sustituyeron en sus ausencias y el cónsul general en Barcelona ${ }^{1}$. No aborda en cambio el tema de las relaciones diplomáticas hispano-italianas en el marco de la política exterior de Primo de Rivera, sobre el que existen sólidas publicaciones (Tusell, Saz, 1982; Palomares, 1989; Sueiro, 1992a; Mugnaini, 1998; Frasca, 2000; Sueiro, 2005; Sueiro, 2013).

\section{Luces y sombras del Directorio Militar}

El contenido de los informes diplomáticos remitidos a Roma, y en concreto a Benito Mussolini, que por entonces llevaba también la cartera de Asuntos exteriores, fue en los primeros tiempos más descriptivo que valorativo y el propio pronunciamiento del 12 de septiembre, bien estudiado por la historiografía española (Tusell, 1987; Olabarri, 1996) no fue objeto de un análisis a fondo, aunque poco a poco fueron apareciendo elementos valorativos del nuevo régimen, ya en la etapa del Directorio Militar, bien analizado ya por la historiografía (González Calbet, 1987).

A propósito del real decreto del 30 de septiembre de 1923 que impuso destitución de concejales de todos los ayuntamientos de España, cuyas funciones serían sumidas por los vocales asociados, el encargado de negocios Mauro Tosti di Valminuta, de noble familia napolitana, destacaba que era la medida más enérgica hasta entonces tomada por el recién formado Directorio Militar y explicaba que en España la política había contaminado todos los organismos

${ }^{1}$ La investigación en que se basa este artículo se inscribe en el proyecto "España en la crisis del sistema liberal: una perspectiva externa, 1917-1936", financiado por el Plan Nacional de I+D+I (HAR2012-31460), y cuyo investigador principal es el profesor Hipólito de la Torre. 
de la administración pública; pero a su vez hacía notar que la universalidad de la medida no beneficiaría a muchos municipios que funcionaban correctamente, ya que los vocales asociados, de representación corporativa, carecían generalmente de la capacidad de gestión que tenían los concejales destituidos². Más favorable se mostró el embajador Raniero Paulucci di Calboli respecto al real decreto de 13 de octubre de 1923 que imponía medidas de incompatibilidad entre los cargos más destacados del Estado y de la empresa privada, porque vendría a eliminar los "escandalosos connubios" que dañaban el prestigio de los políticos y de la propia nación española ${ }^{3}$. Paulucci di Calboli, descendiente de una vieja familia nobiliaria y con una larga trayectoria diplomática iniciada en 1885, compatibilizó su actividad de diplomático en Madrid con la de senador en Roma, lo que explica que la embajada estuviera frecuentemente a cargo de sucesivos encargados de negocios.

En la opinión pública española, los diplomáticos italianos percibieron inicialmente una actitud muy favorable hacia el Directorio Militar. A los tres meses de su constitución, Tosti creía que la aprobación de su gestión era "casi unánime" y que la prensa, aunque se veía privada de la plena libertad de crítica, no había escatimado los elogios. ${ }^{4}$ Respecto a una de las medidas más llamativas de la Dictadura, la extensión a toda España de la milicia voluntaria catalana del Somatén, Tosti escribió un extenso y documentado informe, en la que señaló cierta afinidad de aquel con la Milizia Volontaria per la Sicurezza Nazionale (es decir la milicia fascista, que tras el acceso de Mussolini al poder se había integrado en el aparato del Estado), pero destacó que el llamamiento de Primo de Rivera a incorporarse al mismo había despertado escaso entusiasmo y que en general el pueblo español había mostrado una notable indiferencia ante los últimos acontecimientos. Lo cual conducía al encargado de negocios a la siguiente reflexión sobre la diferencia entre la llegada de Mussolini al poder en octubre de 1922 y la de Primo de Rivera en septiembre de 1923:

"Se engañaría quien pensara que por las calles de Madrid y de las otras ciudades españolas se repita hoy aquel maravilloso espectáculo de juventud y de energía que se vieron en las calles de Roma y de Italia en las jornadas de octubre. Esta frialdad hay que atribuirla en parte al temperamento del pueblo español, pero depende sobre todo de fundamentales diferencias -a pesar de las

\footnotetext{
2 ASD (Archivio Storico Diplomatico, Ministero degli Affari Esteri, Roma, Affari Politici) $1588,1-10-1923$.

${ }^{3}$ ASD 1588, Regia Ambasciata in Madrid: "Provvedimento del Direttorio Militare. Incompatibilitá politiche", 14-X-1923.

${ }^{4}$ ASD 1588, Regia Ambasciata in Madrid: "Riorganizzazione del Direttorio", 26-XII1923.
} 
apariencias- (...) El fascismo tuvo su primer origen en la guerra nacional: se trataba de conservar las ventajas conseguidas con el sacrificio de la floreciente juventud italiana y de reforzar y corroborar el sentimiento patriótico del pueblo italiano contra nefastos partidos y doctrinas que trataban de debilitarlo. Además el fascismo tenía su razón de ser en las luchas sociales y políticas que laceraron al pueblo italiano en los tristes días que siguieron al armisticio, y también en la necesidad de unir en un haz todas las fuerzas jóvenes y sanas del país para salvar a la patria de una ruina inminente.

El gran Somatén español no es el producto de la guerra ni de la lucha de los partidos: nace en virtud de un decreto real, como si sólo por el vigor de la ley pudiera crearse e infundirse en el ánimo del país el sentimiento de la necesidad de una defensa común."

Unos meses después, en abril de 1924, un nuevo encargado de negocios, Macario, atribuía la incapacidad del Directorio para afirmarse a su "imborrable pecado de origen", el de haber surgido de un movimiento pura y exclusivamente militar6. Y en marzo de 1925, el embajador Paulucci resumía la situación política española en la indiferencia de la mayoría y la sorda agitación de las minorías, aunque todos los españoles estaban de acuerdo en que el sistema derribado es septiembre de 1923 no podía resucitar. Los dos grandes partidos históricos estaban muertos y el país estaba harto de las luchas personales ajenas a todo ideal y de los métodos de muy dudosa moralidad que habían caracterizado al viejo parlamentarismo. El nuevo régimen había limitado las libertades de prensa y de reunión, pero el pueblo no parecía preocuparse por ello. Primo de Rivera estaba cometiendo sin embargo muchos errores, de los cuales el más grave era, en opinión del embajador Paulucci, "la guerra a fondo declarada al catalanismo", con la supresión de esa apariencia de privilegio regional que había sido la Mancomunidad y con la ofensiva contra la lengua catalana, que los anteriores gobiernos habían respetado enteramente ${ }^{7}$.

La cuestión catalana fue seguida con atención por la diplomacia italiana. El encargado de negocios Tosti se mostraba escéptico ante los argumentos de aquellos catalanes que consideraban que la unión de su próspera región con España era una "pesada cadena", que redundaba en exclusivo beneficio del resto del país, cuando en realidad, una separación que implicase el establecimiento de barreras aduaneras provocaría la ruina de la industria catalana. En opinión

5 ADS, 1588, Regia Ambasciata in Madrid: "Il 'Somaten' spagnuolo", Madrid, 29-IX1923. Véase Reguillo, 1987.

${ }^{6}$ ADS, 1589, Regia Ambasciata in Madrid: "Situazione interna", Madrid, 13-IV-1924.

${ }^{7}$ ADS, 1590, Regia Ambasciata in Madrid: "Situazione política della Spagna", Madrid, 23-III-1925. 
de Tosti, la política incierta e incluso medrosa de los gobiernos de Madrid había favorecido al separatismo catalán, un estado de cosas al que el Directorio estaba dispuesto a poner fin, por lo que las medidas antiseparatistas previstas por el decreto del 18 de septiembre de 1923, respondían a los deseos mayoritarios de la opinión pública española ${ }^{8}$. El cónsul en Barcelona, destacaba sin embargo que la "enérgica campaña contra el catalanismo" había provocado un tácito descontento, no sólo entre los separatistas, sino entre los autonomistas, que inicialmente habían visto con simpatía el pronunciamiento de Primo de Rivera9. Y el embajador Paulucci se mostraba poco convencido acerca de la prudencia de la política que Primo de Rivera seguía respecto a Cataluña. En marzo de 1925, con ocasión de la aprobación del nuevo Estatuto provincial, que implicó la supresión de la Mancomunidad catalana, expresó su temor de que ello pudiera dar lugar al recrudecimiento de una cuestión que durante años habían sido incapaces de resolver los gobiernos españoles ${ }^{10}$. Por el contrario, el embajador elogió la disposición del estatuto por el que se concedía el voto a la mujer en las elecciones administrativas, siguiendo el ejemplo de los países anglo-sajones, germánicos y escandinavos. que habían comprendido la necesidad y la justicia de del voto femenino, frente a las reticencias de Francia e Italia ${ }^{11}$.

La extrema radicalización de un sector minoritario del separatismo catalán se puso de manifiesto en junio de 1925 con un intento de atentado contra Alfonso XIII y la familia real. Se colocó en la vía férrea una potente bomba que habría debido explotar, al paso del tren real por la costa de Garraf, pero que afortunadamente la policía pudo desactivar a tiempo gracias a una denuncia. Paulucci informó a Roma de la dolorosa sorpresa de Alfonso XIII, quien jamás habría imaginado que los catalanistas pudieran recurrir a medios que hasta entonces habían sido exclusivos de los anarquistas. Pero el embajador se hizo también eco de que incluso en el seno del Directorio se habían producido críticas a la política demasiado intransigente y anti catalana de su Presidente ${ }^{12}$.

El Rey, por otra parte, no ocultaba su rotundo repudio del parlamentarismo. Paulucci informó en abril de 1925 de una conversación de Alfonso XIII

${ }^{8}$ ADS, 1588, Regia Ambasciata in Madrid: "Provvedimenti del nuovo Direttorio contro il separatismo", Madrid, s.d. (septiembre de 1923).

${ }^{9}$ ASD, 1588, Regio Consolato Generale in Barcellona: "Situazione política", 15-X-1923.

${ }^{10}$ ASD, 1590, Regia Ambasciata in Madrid: "Invio testo del nuovo Statuto provinciale", 21-III-1925.

${ }^{11}$ ASD, 1590, Regia Ambasciata in Madrid: "Nuova legge provinciale. Voto amministrativo alle donne", 25-III-1925. Véase Díaz Fernández (2005).

12 ASD, 1590, Regia Ambasciata in Madrid: "Politica interna della Spagna", 10-VI1925. Sobre el complot de Garraf véase González Calleja (1999: 379-383). 
con dos escritores franceses, Jérôme y Jean Tharaud, que no estaba destinada a la publicidad, pero que ellos publicaron en el Paris-Midi y que en España dio a conocer El Sol. "Si se volviese a abrir el Parlamento -les habría dicho- se vería cómo los viejos partidos, que llevaban el país a la ruina, volverían a reanudar sus disputas". El parlamentarismo, según el rey, sólo resultaba ventajoso para unos cuantos políticos, mientras que resultaba indiferente para veinte millones de españoles, que sólo reclamaban seguridad en el trabajo y respeto a sus bienes. España e Italia, concluyó el Rey, ya habían tomado su decisión ${ }^{13}$.

Por su parte los dirigentes de los antiguos partidos monárquicos trabajaban contra el Directorio y, en opinión del encargado de negocios Macario, encontraban apoyo en ambientes intelectuales y en sectores militares, sobre todo entre la oficialidad más joven ${ }^{14}$. Al embajador Paulucci le impresionó mucho la conversación que tuvo, en junio de 1925, con el conde de Romanones, según el cual la posición del Rey era muy insegura, ya que tras los insultos lanzados a todos los políticos, no podría volver a ser un rey constitucional. El líder liberal estimaba además que el catalanismo, al que el Directorio había provocado imprudentemente, era más fuerte que nunca: contaba con hábiles dirigentes, con un amplio apoyo social y con grandes recursos económicos "para la propaganda... y también para los atentados"15.

\section{Dictadura española y fascismo italiano}

La Italia de Mussolini gozó de prestigio en la Dictadura, que trató de inspirarse en las instituciones fascistas, algo que los diplomáticos italianos observaron con satisfacción, aunque también destacaron la limitada capacidad de Primo de Rivera para impulsar al pueblo español hacia una renovación profunda, por lo que en contraste con la gran obra del fascismo les parecía un intento bien intencionado, pero que no llegaba a arraigar.

A los dos días del pronunciamiento de Primo de Rivera, el cónsul general en Barcelona, que había tenido ocasión de informarse de los sentimientos del hasta entonces Capitán General de Cataluña, destacó su admiración y afecto por Italia, de la que habría dicho que representaba un gran ejemplo para todos los pueblos dispuestos a redimirse y salvarse ${ }^{16}$. Durante el viaje de

${ }^{13}$ ASD, 1590, Regia Ambasciata in Madrid, "Dichiarazioni di S.M. il Re Alfonso", 26IV-1925. Sobre el papel del Rey en la Dictadura véase Gómez Navarro (1991: 101-150).

${ }^{14}$ ASD, 1590, Regia Ambasciata in Madrid: "Situazione interna della Spagna", 21-V1925. Véase Seco Serrano, 1986.

${ }^{15}$ ASD, 1590, Regia Ambasciata in Madrid: "Conversazione col Conte di Romanones", s.d. (junio de 1925).

${ }^{16}$ ASD, 1588, Regio Consolato Generale in Barcellona: "Situazione política”, 15-IX-1923. 
los Reyes a Italia en noviembre de 1923, a quienes acompañó Primo de Rivera, las opiniones de este fueron cuidadosamente resumidas en un informe redactado por el militar italiano que formó parte de su séquito. El dictador español se mostró satisfecho de que las buenas relaciones que el gobierno fascista había logrado establecer con la Iglesia, con lo que se había suavizado la "cuestión romana" que en las pasadas décadas había sido el mayor obstáculo para el desarrollo de las relaciones hispano-italianas. Expresó su admiración por la revolución fascista, efectuada dentro de la órbita constitucional y monárquica, y por Mussolini, a quien consideraba una personalidad no sólo italiana sino mundial. Y anunció que "él pretendía seguir, en cuanto era posible y compatible con las exigencias y las características propias de su país, las huellas luminosas marcadas por la Marcha sobre Roma y el Duce fascista" ${ }^{17}$. Por su parte, Alfonso XIII llegó a presentar a Primo de Rivera ante sus interlocutores italianos como "mi Mussolini"18.

Igualmente favorable a la Italia fascista se mostraba el Rey Alfonso XIII. En una entrevista que concedió a Paulucci en marzo de 1926 llegó incluso a sugerir, de acuerdo con su poco diplomática costumbre de decir lo que se le ocurría, una posible retirada de Italia, España, Polonia, Brasil y otros países de la Sociedad de Naciones "que Wilson había fundado sobre la masonería", para construir otra más seria y justa "fundada sobre la cruz". El prudente embajador comunicó a Roma que se limitó a dejar hablar al Rey sin pronunciarse sobre sus audaces propuestas ${ }^{19}$. Y aún más audaz se mostró Alfonso XIII con el embajador Giuseppe Medici cuando en enero de 1928 le dijo que en una próxima guerra Italia, España y Alemania se encontrarían en el bando opuesto al de Francia, al tiempo que le comentaba lo bueno que sería si Italia pudiera prestarle a Mussolini a España por seis meses, una boutade tan halagadora respecto al dictador italiano como implícitamente despectiva hacia el español ${ }^{20}$. Su hostilidad hacia París y su admiración hacia Roma reaparecieron unos meses más tarde en una conversación en la que el Rey, quien "según su costumbre" no se mostró reticente en mostrar sus opiniones, dijo prever una ruptura definitiva entre Italia y Francia, palabras que el embajador se limitó "a escuchar con la debida reserva" 21.

${ }^{17}$ ASD, 1588, Maggiore Augusto Spechel, "Notizie confidenziali su impressioni raccolte ed osservazoni e dichiarazioni fatte da S.E. il generale Primo de Rivera, Presidente del Direttorio spagnuolo, durante la permanenza in Roma (19-23 novembre 1923)", 25-XI-1923.

${ }^{18}$ ABC, 22-XI-1923.

19 ASD, 1590, "Colloquio fra il R. Ambasciatore e li Re di Spagna", 13-III-1926.

${ }^{20}$ ASD, 1591, Regia Ambasciata in Madrid: "Conversazione con Re Alfonso", 10-I-1928.

${ }^{21}$ ASD, 1591, Regia Ambasciata in Madrid: "Colloquio con Sua Maestà Re Alfonso", 18-XII-1928. 
La corriente de simpatía hacia el fascismo italiano fue apreciada por el nuncio del Vaticano en España, monseñor Federico Tedeschini, él mismo suficientemente próximo al fascismo como para haber comentado al embajador Paulucci, en noviembre de 1924, su disgusto por el "aprovechamiento" verdaderamente indigno que las oposiciones habían hecho del delito Matteotti (es decir el asesinato de un diputado socialistas por fascistas, que desencadenó una tardía e infructuosa unión de diferentes sectores opuestos al fascismo) y haberse mostrado muy crítico hacia la conducta política (antifascista) de Don Sturzo, el gran inspirador del Partito Popolare (antecedente de la democracia cristiana), a quien sin embargo respetaba como sacerdote de conducta ejemplar y gran inteligencia ${ }^{22}$. Al siguiente embajador, Giuseppe Medici, Tedeschini le dijo en abril de 1927 que, en contraste con lo que ocurría cuatro o cinco años antes, Italia gozaba entonces de un gran prestigio en todos los estratos de la nación española. El nuncio, dispuesto a colaborar en todo con el embajador, dado que se sentía "sobre todo italiano", opinaba por entonces que la posición de Primo de Rivera era muy sólida ${ }^{23}$.

La identificación del régimen con el modelo italiano se tradujo por otra parte en una creciente tendencia antifascista en la oposición. En una entrevista con Primo de Rivera, celebrada en diciembre de 1928, en la que el dictador explicó que seguía con simpatía y provecho las profundas transformaciones que Mussolini estaba efectuado en el Estado fascista, el embajador Medici le hizo notar que últimamente se habían acentuado los discursos retóricamente antifascistas de muchos diarios madrileños. Ante ello Primo de Rivera declaró que nada le importaba más que el fascismo y que no paraba de lanzar advertencias e imponer multas, pero que él no era enteramente el árbitro de la prensa española. El embajador suponía que, tratando de evitar los rigores de la censura, la prensa lanzaba ataques al fascismo lejano para que recayeran en la dictadura cercana ${ }^{24}$.

La admiración hacia el fascismo no implicaba, en opinión de los diplomáticos italianos, que se estuviera construyendo en España un régimen equiparable al de Mussolini. En particular la Unión Patriótica, el partido oficial creado por Primo de Rivera, era "una palidísima imitación de los Fasci", en palabras de Giusepe Medici en 1928. La diferencia, según el embajador, es que en Italia eran los Fasci los que habían creado el régimen, mientras que en España era el régimen el que pretendía crear las Uniones Patrióticas. El Somatén tam-

\footnotetext{
${ }^{22}$ ASD, 1589, Regia Ambasciata in Madrid, 27-XI-1924.

${ }^{23}$ ASD, 1591, telegrama, Medici: "Rapporti tra Spagna e Italia. Colloquio R. Ambasciatore con Nunzio apostólico", 1-IV-1927.

${ }^{24}$ ASD, 1591, Regia Ambasciata in Madrid: "Situazione generale interna", 9-XII-1928.
} 
poco podía compararse con la Milicia Voluntaria italiana, ni por número de miembros, ni por armamento, ni por disciplina ni, sobre todo, por fuerza y cohesión espiritual. Así es que la Dictadura, que se presentaba como apolítica, se apoyaba sobre todo en "las simpatías de la mayoría de la nación que indiferente, por atávica tendencia del alma española, a las luchas político-parlamentarias, se adapta hoy con espíritu receptivo a la duradera tranquilidad interna y a la difusa prosperidad económica que pocos años de gobierno fuerte han visiblemente asegurado al país"25.

Ese énfasis en la aquiescencia un tanto pasiva de la población y en la endeblez política de la Unión Patriótica estuvo presente en los informes diplomáticos italianos a lo largo de toda la Dictadura. En abril de 1924 el encargado de negocios Macario se refería a la mediocridad de los dirigentes de la Unión Patriótica y expresaba sus dudas en que esta pudiera lograr su propósito de convertirse en un gran partido ${ }^{26}$. Un año después, el embajador Paulucci informaba que un extenso manifiesto publicado por la Unión Patriótica había sido recibido "con la máxima indiferencia"27. Y en enero de 1929, el cónsul general en Barcelona sostenía que la Unión Patriótica era "una creación ficticia querida por la Dictadura para formarse una clientela política más allá del círculo restringido de las esferas militares al que el pronunciamiento debió su éxito" y que su influencia en la vida política española era casi irrelevante. Aunque se la comparara a menudo con el Partido Fascista, la diferencia entre ambos era sustancial ${ }^{28}$.

\section{Tranquilidad general y tensiones puntuales bajo el Directorio Civil}

En septiembre de 1925 Primo de Rivera logró un éxito militar que tuvo una alta rentabilidad política, cuando con el desembarco de Alhucemas pudo comenzar la pacificación del protectorado de Marruecos, poniendo fin a un prolongado conflicto que había contribuido mucho al desprestigio del anterior régimen parlamentario. Poco después se dieron los primeros pasos para que la dictadura militar de carácter provisional establecida en 1923 se consolidara en un régimen duradero. En diciembre de 1925 el Directorio Militar fue sustituido por un Directorio Civil, presidido también por el general Primo De

25 ASD, 1591, Regia Ambasciata in Madrid: "Anniversario del colpo di Stato", 5-IX-1928. Sobre la Unión Patriótica véanse Gómez Navarro (1991: 261-304) y Quiroga Fernández de Soto (2005).

${ }^{26}$ ASD, 1589, Regia Ambasciata in Madrid: "Situazione interna", 16-IV-1824.

${ }^{27}$ ASD, 1590, Regia Ambasciata in Madrid: "Unione Patriottica. Suo manifestó", 7-IV1925.

${ }^{28}$ ASD, 1592, Regio Consolato Generale in Barcellona: "L'Unione Patriottica", 15-I-1929. 
Rivera, y en septiembre de 1927 el Rey dio su consentimiento a la convocatoria de una Asamblea Nacional Consultiva, de carácter corporativo, que en un plazo de tres años habría de acordar un anteproyecto de legislación general, que vendría a enterrar definitivamente el régimen liberal parlamentario (Gómez Navarro, 1991: 261-304; Álvarez Chillida, 1996). Meses atrás Primo de Rivera había informado ya a Mussolini de que tenía el proyecto de sustituir al Parlamento por una Asamblea Nacional ante la que se presentarían los planes para una nueva organización del Estado, en muchos aspectos coincidente con la impulsada por aquel en Italia ${ }^{29}$.

Los años del Directorio Civil fueron una etapa de tranquilidad general, en los que sin embargo el régimen se enfrentó a manifestaciones de descontento más o menos graves en el seno de Ejército, en Cataluña, entre los intelectuales e incluso en el clero. Dos grandes exposiciones inauguradas en mayo de 1929, la Exposición Iberoamericana de Sevilla y la Exposición Universal de Barcelona permitieron presentar a la España de Primo de Rivera su mejor imagen, como observaron los diplomáticos italianos. Según el embajador Medici, ambas eran admirables por la grandiosidad de su concepción y su ejecución y eran expresión concreta de la voluntad renovadora de la nueva y próspera España. En Barcelona, donde se habían temido disturbios y atentados, el orden público no fue perturbado, la ciudad tenía un aspecto de intensa animación y las aclamaciones al Soberano y al Jefe del Gobierno fueron unánimes y nutridas. El éxito había fortalecido a Primo de Rivera y contribuido al restablecimiento de la armonía entre Rey y Dictador. "El pueblo está conmigo -dijo éste al embajador-y abandonaré el poder sólo si y cuando querré"30.

En realidad dimitió tan sólo diez meses después, así es que su régimen no era tan sólido como lo parecía en el ambiente triunfal de aquellas exposiciones. Había descontento en Cataluña, donde la dictadura se había enfrentado a sectores tan representativos como el Colegio de Abogados, cuya Junta directiva fue desterrada, o el Fútbol Club Barcelona. Por otra parte, el cónsul general en Barcelona, destacaba la potencia cultural del catalanismo:

"La característica intelectual, cultural dada al movimiento catalán es quizá la explicación de su subsistencia, a pesar de la tenaz persecución que ha sufrido desde septiembre de 1923. (...) El movimiento comunista (expresión con la que el cónsul se refería en realidad al anarcosindicalismo) ha sido destruido en Cataluña, porque se basaba principalmente en la fuerza y con la fuerza ha

${ }^{29}$ Documenti Diplomatici Italiani, Roma, Istituto Poliografico dello Stato, VII serie, vol. V, pp. 48-49, Primo de Rivera, 4-III-1927.

${ }^{30}$ ASD, 1592, Regia Ambasciata in Madrid:"Esposizione italiana, Rappresentanza italiana. Situazione política", 23-V-1929. Véase Domínguez Méndez (2013). 
sido derrotado. A movimiento catalán que tenía un fondo intelectual se le ha opuesto inútilmente la fuerza. En política hay que usar medios homeopáticos: a la violencia hay que contraponer la violencia, pero a la fe hay que contraponer otra fe. Esto quizá no lo han entendido en Madrid, lo que no es de extrañar tratándose de militares."31

El sector más radical del nacionalismo catalán, encabezado por el coronel Francesc Macià, exiliado en Francia, optó sin embargo por la opción paramilitar mediante la entrada de grupos armados por la frontera pirenaica, intentona que fue evitada por las autoridades francesas: fue el llamado complot de Prats de Molló. El cónsul general observó que la intentona había carecido de preparativos en el interior de Cataluña y la atribuyó al carácter exaltado de Macià y al "deseo de atraer la atención de Europa hacia el problema catalán que iba resolviéndose y que no podía dar lugar a hechos sensacionales, siendo los catalanes muy ajenos a hacer sacrificios por su pretendida causa"32. Y también se hizo eco de que la prensa catalanista habían aprovechado la intentona y el "caso Garibaldi" para reforzar su campaña contra el fascismo, atribuyéndole "pretendidas responsabilidades"33. En realidad, en la intentona habían participado unas decenas de italianos, reclutados por Riciotti Garibaldi Jr., nieto del héroe nacional, exiliado antifascista... y agente provocador a sueldo del Estado italiano, que manipuló la conspiración con el objetivo de envenenar las relaciones entre España y Francia (Sueiro, 1992b).

Más peligroso para el régimen que esta conspiración un tanto bufa de Macià, que sin embargo contribuyó a incrementar su prestigio entre los nacionalistas, fue la oposición que encontró en sectores del propio Ejército español (Boyd, 1990: 324-360; Gómez Navarro, 1991: 353-390; González Calleja, 1999: 447-493). Los diplomáticos italianos prestaron gran atención al conflicto con el cuerpo de Artillería, que se negó en pleno a aprobar el nuevo sistema de ascensos decretado por el Directorio, contrario al solemne compromiso de los oficiales de artillería de no aceptar más ascensos que los debidos a la antigüedad para evitar favoritismos. Un informe de la embajada, en octubre de 1926, informó de las dudas sobre la respuesta que Primo de Rivera iba a dar al conflicto, pues si bien en un principio pareció inclinarse por medidas de rigor y llegó a amenazar con hacer fusilar a cinco coroneles, luego optó por hacer fren-

${ }^{31}$ ASD, 1590, Regio Consolato Generale in Barcellona, "Situazione política locale", 30-V-1926. Véase Roig Rosich (1992).

32 ASD, 1590, Regio Consolato Generale in Barcellona, "Situazione política locale", 10-XI-1926.

33 ASD, 1590, Regio Consolato Generale in Barcellona, "Situazione política locale", 15-XI-1926. 
te a aquel gravísimo acto de indisciplina de manera más moderada, como le habían recomendado el Rey, algunos ministros y amigos y también el nuncio. ${ }^{34}$ Los oficiales de artillería fueron suspendidos de empleo y sueldo y medio millar de ellos se negaron a reincorporarse en las condiciones exigidas, encontrando el apoyo económico de otros oficiales, un "acto de solidaridad malentendida" que en opinión del encargado de negocios era "contrario al más elemental sentido de disciplina y de espíritu militar" 35 . Primo de Rivera se habría visto obligado a suavizar las condiciones de readmisión, después de que el rey su hubiera negado a firmar el 17 de noviembre un decreto más severo ${ }^{36}$.

En noviembre de 1928, a propósito de importantes cambios en la cúpula militar realizados por Primo de Rivera, el encargado de negocios envió a Roma un despacho en el que resumió la relación entre el Dictador y el Ejército en estos términos:

"Para comprender las repercusiones que una tan amplia remodelación de los altos cargos del ejército ha tenido en la opinión pública y las innumerables hipótesis que se proponen para tratar de explicarla, hay que recordar la importancia política que el ejército ha tenido siempre en este país y sobre todo desde el 13 de septiembre de 1923 tras el golpe de Estado del que surgió la actual dictadura, importancia política que Primo de Rivera ha tratado siempre de eliminar desde el momento en que asumió el poder.

Cierto es que en el complot denominado 'de la noche de San Juan' del 24 de junio de 1926, y a continuación en los demás complots contra el actual régimen descubiertos en 1927 y 1928, han estado siempre implicados elementos del ejército; que los partidos políticos de la oposición legal y extra-legal siguen buscando en el ejército solidaridad y complicidad, y que el descontento de una parte de las fuerzas armadas del Estado contra el Gobierno personal de Primo de Rivera, aunque no osa manifestarse abiertamente, de hecho subsiste." 37

Las relaciones entre la Dictadura y la Iglesia fueron generalmente buenas y los activistas católicos representaron inicialmente uno de los principales apoyos del régimen, pero no faltaron los problemas, desde la ofensiva del régimen contra el apoyo eclesial al catalanismo hasta la disputa por el control del sistema educativo, y en los momentos finales de la Dictadura el apoyo católico se debilitó (Adagio, 2004; Cárcel Ortí, 2007; Corts i Blay, 2010; Quiroga, 2013; Martínez Álvarez, 2015). El encargado de negocios italiano se hizo eco, en

\footnotetext{
${ }^{34}$ ASD, 1590, Regia Ambasciata in Madrid, 20-X-1926.

35 ASD, 1590, Regia Ambasciata in Madrid, "Situazione política interna e malumore nell'esercito spagnuolo", 7-XI-1926.

${ }^{36}$ ASD, 1590, Regia Ambasciata in Madrid, 23-XI-1926. Sobre el conflicto artillero véase González Calleja (1999: 466-481).

${ }^{37}$ ASD, 1591, Regia Ambasciata in Madrid, "Situazione política", 4-11-1928.
} 
noviembre de 1928, del "vivo descontento" que desde hacía tiempo estaba latente en el clero español y había salido a la luz al aproximarse el debate presupuestario. En tres notas dirigidas al jefe del Gobierno, que publicó El Debate, los arzobispos españoles deploraron las miserables condiciones económicas del clero, cuya dotación por parte del Estado no se había acompasado al incremento del coste de la vida; llamaron la atención sobre "la oleada de pornografía" que invadía el país; y aludieron a las frecuentes infracciones del descanso dominical. El diario oficioso La Nación publicó un artículo, atribuido a Primo de Rivera, que deploró el contenido de tales notas y sobre todo que hubieran sido publicadas ${ }^{38}$. Sin embargo, el gobierno optó por otorgar un aumento significativo del presupuesto del clero, que apenas se había incrementado desde 1920, y con ello resolvió al menos de momento, según el embajador Medici, "una cuestión que amenazaba con agravar el disenso existente desde hacía tiempo entre el clero y el Gobierno", tema en el que la opinión pública tendía a ponerse a favor del clero ${ }^{39}$.

\section{El declive final del régimen}

El año 1929 se inició con un frustrado pronunciamiento militar, que sólo se materializó con la sublevación de un regimiento de artillería en Ciudad Real el día 28 de enero, pero que se apoyaba en una vasta conspiración encabezada por el líder conservador José Sánchez Guerra, quien no logró sublevar a la guarnición de Valencia (González Calleja,1999: 482-493). Y terminó en un clima de dificultades económicas y de agotamiento del régimen, que conduciría a la dimisión de Primo de Rivera en enero de 1930. Fue un proceso observado con atención por la diplomacia italiana, que registró los vaivenes entre momentos de deterioro y de aparente consolidación del régimen.

El embajador Medici se mostró inicialmente optimista tras el fracaso del pronunciamiento: el Gobierno había demostrado autoridad y tenía controlado al grueso del Ejército ${ }^{40}$. Respecto a las medidas represivas que se fueran a tomar, hacía constar que la opinión parecía oponerse de entrada a las penas capitales, pero él mismo estimaba que la indulgencia se había demostrado hasta entonces ineficaz ${ }^{41}$. Cuando en septiembre de 1926 había surgido el conflicto artillero, la severidad inicial del Gobierno, que disolvió el cuerpo de Artillería,

\footnotetext{
${ }^{38}$ ASD, 1591, Regia Ambasciata in Madrid, "Agitazione nel clero spagnuolo", 6-XI-1928.

${ }^{39}$ ASD, 1591, Regia Ambasciata in Madrid, "Assemblea Nazionale. Situazione económica del clero spagnuolo", 14-XII-1928.

${ }^{40}$ ASD, 1592, Regia Ambasciata in Madrid, "Sedizione militare", 30-I-1929.

${ }^{41}$ ASD, 1592, Regia Ambasciata in Madrid, "Sedizione militare", 31-I-1929.
} 
domó rápidamente la rebelión, pero luego Primero de Rivera había cedido a las presiones del Rey, de la alta sociedad y del clero, y también a su propia naturaleza benévola, y había abierto la posibilidad de reingreso a los oficiales de artillería, una clemencia que había resultado contraproducente, pues la agitación había continuado. Y tras la nueva sedición, se habían evitado los castigos inmediatos y ejemplares. "El país no quiere derramamientos de sangre", le había dicho el propio Primo de Rivera, y el embajador comprendía el carácter "bondadoso y paternal, indulgente y sonriente" que aquel había dado a su dictadura y que le había asegurado, si no el entusiasmo, al menos la simpatía del pueblo, no podía cambiarse de repente. Tampoco le convenía a Primo de Rivera una excesiva severidad, dado que él mismo debía su llegada al poder a una sedición militar ${ }^{42}$.

Algunas medidas tomadas a comienzos de febrero, entre las que el embajador destacó la creación de un tribunal especial dependiente del ministerio de Gobernación y encargado de los delitos contra la seguridad del Estado, parecieron marcar un cambio de orientación. Su inspiración en las leyes fascistas era a juicio de Medici evidente ${ }^{43}$. En su opinión, la rebelión había fracasado por falta de valor y decisión en sus jefes y por la indiferencia mayoritaria de la opinión pública, que comprendía como los adversarios de la Dictadura aprovechaban el descontento militar para sus propios fines, mientras que las clases trabajadoras se negaban a participar en movimientos revolucionarios. Por otra parte, la abundancia de notas oficiosas y declaraciones justificativas por parte de la Dictadura le hacían pensar que Primo de Rivera estaba recurriendo a la persuasión porque el ambiente de la opinión no le permitía imponerse por la fuerza ${ }^{44}$. Su valoración general del estado anímico de los españoles era el siguiente:

"En su conjunto la nación española se muestra agradecida al general Primo de Rivera por haber restablecido la paz en un país al que turbaban peligrosamente la política ciega de unos pocos partidos y las pasiones revolucionarias de unos pocos grupos. Sin duda España se fortalece económicamente por una recta administración, un progresivo potenciamiento de la agricultura, una amplia política de obras públicas y un difuso bienestar: pero quizá justo porque el país se ha satisfecho de manera egoísta por esta cómoda prosperidad

\footnotetext{
II-1929.

${ }^{43}$ ASD, 1592, Regia Ambasciata in Madrid, "Provvedimenti governativi in seguito ultima sedizione militare", 5-II-1929.

${ }^{44}$ ASD, 1592, Regia Ambasciata in Madrid, "Provvedimenti governativi in seguito sedizione militare", 11-II-1929.
}

${ }^{42}$ ASD, 1592, Regia Ambasciata in Madrid, "Rivolta militare del 29 gennaio 1929", 3- 
material, no se puede todavía afirmar que paralelamente se haya desarrollado un nuevo espíritu nacional colectivo. La opinión pública está ausente y eso explica por qué intereses corporativos o veleidades de facciones apartadas del poder puedan a veces todavía aflorar o prevalecer, como en el reciente tentativo rebelde, entre la indiferencia del público y, en muchos aspectos, la benevolencia indulgente del mismo Gobierno. Benevolencia que a esos intereses y esas facciones puede parecer un signo de debilidad que les da ánimo, pero que sin duda debe responder a un genérico sentimiento innato y dominante si un gobierno dictatorial, con acuerdo de todos los ministros, ha optado por la vía de la clemencia y no ha encontrado la voluntad o no ha tenido la posibilidad de sancionar con rigor a los rebeldes culpables, como habría ocurrido en cualquier otro país, tolerando, con la aprobación de la opinión pública, que a tres semanas ya de los acontecimientos de Ciudad Real y de Valencia, no se haya pronunciado ninguna sentencia capital ni se haya acordado ningún castigo ejemplar." 45

En marzo de 1929 se le abrió un nuevo frente a la Dictadura con las masivas protestas de los estudiantes universitarios en contra de una ley aprobada el año anterior que abría la posibilidad de que centros privados de enseñanza que cumplieran determinadas exigencias (en la práctica los centros católicos de Deusto y El Escorial) concedieran títulos universitarios (García Queipo de Llano, 1987). El embajador Medici dio crédito a la versión oficial de que los estudiantes se habían dejado engañar por agitadores profesionales, pero observó que la facilidad con que el movimiento había cobrado fuerza demostraba "la escasa adhesión espiritual de la juventud al régimen"46. Concedía por otra parte crédito a la versión según la cual la masonería nacional y la internacional, sobre todo la francesa, contribuían bajo cuerda a la agitación ${ }^{47}$. Por su parte Primo de Rivera le comentó que la protesta universitaria no representaba un problema grave, pero que los estudiantes eran como las moscas, que cuantas más se aplastan más salen, y añadió que él se proponía actuar "como un fascista", sin más precisión que una referencia al manganello (la prototípica porra utilizada por los fascistas italianos contra sus enemigos en los años previos a la toma del poder) y una pregunta acerca de cómo se había procedido en Italia a la fascistización de profesores y estudiantes ${ }^{48}$. Sin embargo, un decreto que facultaba la colaboración del Somatén en el mantenimiento del orden público fue muy mal recibido por sus miembros, que no querían verse impli-

\footnotetext{
${ }^{45}$ ASD, 1592, Regia Ambasciata in Madrid, "Situazione política in Spagna", 17-II-1929.

${ }^{46}$ ASD, 1592, Regia Ambasciata in Madrid, "Agitazione studentesca. Situazione política", 11-III-1929.

${ }^{47}$ ASD, 1592, Regia Ambasciata in Madrid, "Situazione política", 29-IV-1929.

${ }^{48}$ ASD, 1592, Regia Ambasciata in Madrid, "Movimento studentesco", 14-III-1929.
} 
cados en labores policiacas, según el embajador. Este por entonces veía oscuro el panorama, con la depreciación de la peseta, la multiplicación de panfletos contra el régimen y la acentuación de las medidas de vigilancia en Madrid, aunque no faltaban las manifestaciones de adhesión a Primo de Rivera ${ }^{49}$.

El prestigio de Alfonso XIII también se debilitaba. El embajador Medici se hacía eco de las críticas que circulaban en medios aristocráticos que le reprochaban haberse dejado dominar por el dictador, haberse aislado respecto a sus más fieles consejeros y a la opinión pública, y haber perdido capacidad de iniciativa. Entre tanto se depreciaban la peseta, los bonos del Estado y las acciones cotizadas en Bolsa, mientras que el espíritu de fronda persistía en el Ejército. Primo de Rivera replicaba prodigando a la opinión pública "sermones, advertencias, comunicados oficiosos y oficiales, declaraciones, justificaciones e incluso amenazas", que tenían cada vez menos efecto, porque se interpretaban como signos de dudas y de debilidad. No había un peligro inminente, pero la dictadura y el dictador perdían popularidad y había incluso quien creía que la propia monarquía estaba en crisis. El Rey Alfonso había demostrado ser débil e indeciso y esas tendencias naturales de su carácter se habían acentuado por entonces por el sincero dolor que le había provocada la muerte de su madre, con quien había perdido a una segura y experta consejera. Respecto a Primo de Rivera, la opinión dominante era que, cumplidas las tareas de restablecer el orden, pacificar Marruecos y consolidar la economía, su misión había acabado ${ }^{50}$. En una entrevista con el embajador, a fines de junio, el dictador se mostró confiado en la estabilidad de su gobierno, fundado en el consenso de la mayor parte del pueblo, pero le confesó que estaba físicamente cansado ${ }^{51}$. De hecho, padecía diabetes.

La admiración de Primo de Rivera por el fascismo le llevó en julio de 1929 al insólito gesto de entregar al embajador italiano los proyectos de unas nuevas leyes constitucionales antes de darlas a conocer en España y de rogar que el propio Mussolini los examinara o hiciera examinar, pues agradecería muchísimo toda sugerencia que le hiciera. El embajador observó que el nuevo sistema constitucional daba primacía al poder ejecutivo, de manera que la Dictadura podría continuar sin límites serios, que las nuevas Cortes unicamerales tendrían una misión muy reducida, mientras que se incrementaría el poder del Rey, que sería asesorado por un reducido Consejo del Reino, inspirado en el Gran Consejo fascista según le había reconocido Primo de Rivera. Medici

\footnotetext{
49 ASD, 1592, Regia Ambasciata in Madrid, "Agitazione scolastica", 23-IV-1929.

${ }^{50}$ ASD, 1592, Regia Ambasciata in Madrid, "Situazione política", 29-IV-1929.

51 ASD, 1592, Regia Ambasciata in Madrid, "Riorganizzazione Arma d'Artiglieria. Situazione política", 23-VI-1929.
} 
consideraba que el Consejo del Reino era el elemento central del nuevo edificio constitucional, pero no veía claro qué papel iba a jugar en la práctica. La relativa libertad concedida a la prensa para analizar el proyecto había permitido a los periódicos liberales y democráticos manifestar su rechazo pleno, mientras que la mayoría de la población se mostraba indiferente. Los pocos periódicos de tendencia más derechista se había limitado a mostrar "una frígida simpatía" cargada de reservas. El propio embajador dudaba que pudiera resultar efectivo un sistema de representación que era vez individual y corporativo, electivo y de nombramiento real ${ }^{52}$.

Mussolini encargó un pequeño informe sobre el proyecto constitucional, cuyo redactor observó que sin duda se inspiraba en principio y órganos fascistas, pero destacó una vez más las diferencias entre ambos regímenes:

"Pero la Revolución Fascista ha sido pasión, lucha, sangre y tenía en sí tres elementos, sin los cuales es muy difícil que se produzca el milagro de infundir a un pueblo una nueva norma de vida: una guerra vencida, un condottiero (caudillo guerrero), un mito.

El meritorio movimiento de Primo de Rivera en España, en cambio, aunque haya sido indiscutiblemente algo más que una crisis ministerial, ha sido ciertamente mucho menos que una revolución. Faltaba la guerra vencida; el mito estaba terriblemente ausente como lo ha demostrado la patética prueba del intento de construcción de un 'partido patriótico' sin ánimo y sin empuje, y el condottiero no puede decirse que haya sido más que un caballero enérgico e inteligente, que además no tenía unos seguidores numerosos ni entusiastas, y se ha visto más frenado que estimulado en muchas de sus iniciativas." ${ }^{13}$

En consonancia con todo ello, el proyecto constitucional era un ecléctico mosaico de buenas intenciones, en el que "junto a alguna innovación de imitación fascista, se mantenían amplísimas concesiones al radicalismo democrático", por lo cual el informe proponía que a la consulta de Primo de Rivera se le diera una respuesta vaga. Mussolini estuvo de acuerdo.

La ampliación de los escaños en la Asamblea Nacional Consultiva, que había de deliberar sobre el proyecto constitucional, permitió a los medios intelectuales demostrar, en palabras de Medici, "su irreductible e implacable oposición" a la Dictadura y al dictador. La Academia de Jurisprudencia y Legislación rehusó nombrar representantes, la de Ciencias Morales y Políticas nombró al ex jefe de Gobierno conservador Sánchez de Toca, que había mostrado su rechazo a participar en la Asamblea, la Universidad de Oviedo al líder reformista

52 ASD, 1592, Regia Ambasciata in Madrid, "Riforma costituzionale", 9-VII-1929 y 17VII-1929. Véase Álvarez Chillida (1996).

53 ASD, 1592, "Promemoria sulla nuova Costituzione spagnuola", sin fecha. 
Melquiades Álvarez, que se negaba a colaborar con la Dictadura, la de Valladolid al exiliado Unamuno, duro crítico del régimen, y el Colegio de Abogados de Madrid votó a una lista encabezada por Sánchez Guerra, principal impulsor de la insurrección militar de enero, todavía encarcelado ${ }^{54}$.

A primeros de noviembre el embajador italiano se hacía eco de la preocupación de "los observadores más objetivos" ante el caos al que conduciría una súbita desaparición de la Dictadura, cuando faltaban una nueva ley constitucional y una sólida educación cívica y política de las masas. En su opinión tres factores habían conducido sobre todo a la atmósfera de crisis existente: las dificultades financieras, agravadas por la política "incierta y contradictoria" del ministro del ramo (José Calvo Sotelo); la absolución de Sánchez Guerra en un Consejo de Guerra presidido por el general Fernando Berenguer, hermano del teniente general Dámaso Berenguer, jefe de la Casa Militar del Rey, que mostraba de nuevo el espíritu de fronda existente en el Ejército; y la propaganda de los partidos de la oposición y de los intelectuales, apoyada por la prensa. El embajador creía sin embargo que el régimen podía contar con la masa del pueblo, con gran parte de las fuerzas productivas, a las que había dado ímpetu, con parte del Ejército y con la Guardia Civil, dirigida por el general Sanjurjo, hombre de confianza del dictador ${ }^{55}$. La absolución de Sánchez Guerra le parecía al embajador el golpe político y moral más duro que había sufrido el régimen. A finales de noviembre corrían además insistentes rumores acerca de una ruptura definitiva entre el Dictador y el Rey, preocupado este por el aislamiento al que el régimen le había llevado ${ }^{56}$.

A comienzos de diciembre Primo de Rivera le explicó al embajador Medici un plan político que incluía la reapertura de la Asamblea Nacional en enero, la pronta celebración de elecciones municipales, a las que seguirían las provinciales, teniendo la certeza de que en ambas vencería la Unión Patriótica, y en el otoño de 1930 las elecciones para la formación de un parlamento unicameral, al que correspondería deliberar sobre la constitución definitiva. Se procedería así a una liquidación pacífica y honorable de la Dictadura, apoyada por el Rey, que de no haber contratiempos le permitiría abandonar el gobierno dictatorial en 1931. Él era quince años mayor que Mussolini, le dijo al embajador, y no contaba con mucho tiempo y además carecía de un partido sólidamente cons-

\footnotetext{
${ }^{54}$ ASD, 1592, "La Dittatura e l'opposizione degli intellettuali”, 7-X-1929. Véase García Queipo de Llano (1988).

55 ASD, 1592, Regia Ambasciata in Madrid, "Improvviso mutamento della situazione politica", 5-XI-1929.

${ }^{56}$ ASD, 1592, Regia Ambasciata in Madrid, "Situazione política", 20-XI-1929.
} 
tituido. De hecho Medici dudaba que la Unión Patriótica pudiera lograr los éxitos electorales en que se basaba el plan del dictador. Pocos días después Primo de Rivera declaró que había renunciado a que la nueva Constitución fuera aprobada bajo su gobierno, de lo que el embajador dedujo que se había abierto la crisis del régimen. Sin embargo todo ello preocupaba poco a la masa de la población, que en los últimos días del año parecía más interesada por la Lotería y por la gastronomía navideña $a^{57}$.

A continuación todo se aceleró y una secuencia de acontecimientos descrita con precisión por el embajador Medici y el encargado de negocios di Peppo condujo a la dimisión de Primo de Rivera el 28 de enero de 1931 (BenAmi, 1983: 245-255; Tusell, 1995). El 31 de diciembre hubo un Consejo de ministros presidido por el Rey, en el que Primo de Rivera presentó un plan político para el final de la Dictadura, que suponía su prolongación durante seis meses hasta la celebración de elecciones generales, acordándose que Alfonso XIII lo estudiaría durante unos días antes de dar su opinión. El plan, según Medici, carecía casi por completo de apoyos, mientras que la depreciación de la peseta provocaba una creciente preocupación. En tales circunstancias, "ante la indiferencia de las masas, la tibia adhesión de las Uniones Patrióticas, la obstinada oposición de políticos e intelectuales y la latente veleidad de revuelta de algunos sectores del Ejército", en palabras de di Peppo, el 26 de enero Primo de Rivera informó a la opinión pública que había planteado a las máximas autoridades militares si conservaba el apoyo del Ejército y dimitiría si lo había perdido. La respuesta delos capitanes generales habría expresado su absoluta devoción a la monarquía, pero habría sido ambigua respecto al Dictador. De hecho, este dimitió el día 28 de enero y dos días después explicó en una entrevista concedida al director de La Nación, que su decisión de consultar a las Fuerzas Armadas se remontaba a los últimos días de diciembre y se debió a la falta de confianza del Rey en su plan para la pacífica liquidación de la Dictadura. El Rey le había expresado su desaprobación por la forma en que había planteado la consulta en un coloquio que tuvieron el día 26, momento a partir del cual se consideró dimisionario, incluso antes de que dieran su respuesta los capitanes generales ${ }^{58}$.

\footnotetext{
${ }^{57}$ ASD, 1592, Regia Ambasciata in Madrid, "Situazione política", 11-XII-1929.17-XII1929 y 24-XII-1929.

58 ASD, 1593, Regia Ambasciata in Madrid, "Situazione política", 1-I-1930; "Cronaca política", 7-I-1930; "Situazione política ed económica", 15-I-1930; "Consultazione delle Forze Armate dello Stato", 27-I-1930; "Fulminea crisi della Dittatura di Primo de Rivera", 29-I-1930; "Ritiro Primo De Rivera", 31-I-1930; Ministero degli Affari Esteri, 13-2-1930.
} 


\section{Conclusiones}

En la percepción del régimen de Primo de Rivera por los diplomáticos italianos hay sobre todo cuatro elementos que conviene destacar por lo que pueden aportar al debate historiográfico sobre su interpretación: la admiración sincera y permanente del Dictador hacia el modelo fascista, las diferencias sustanciales entre las experiencias italiana y española, la indiferencia política de la mayoría de la población y la relativa moderación de la Dictadura frente a sus enemigos. Al tratar de estos temas, que se repiten una y otra vez en los informes, es visible un sentimiento de superioridad por parte de los diplomáticos italianos, que ven en la admiración hacia el fascismo la prueba del nuevo prestigio de su país, consideran que la experiencia española queda muy lejos de la transformación sustantiva que se está produciendo en Italia, contrastan la apatía de los españoles con la movilización del sentimiento nacional en España y consideran que la clemencia de la Dictadura española, en implícito contraste con el rigor fascista, es una prueba de debilidad.

Todo ello encaja bien con las pautas interpretativas que predominan en la historiografía (Olábarri Gortázar, 1995; González Calleja, 2007; Montes, 2012; López Îniguez, 2015). Sin entrar a fondo en el análisis, cabe recordar las interpretaciones defendidas en algunas de las obras de conjunto más significativas sobre el tema, las de Ben-Ami, Gómez Navarro y Tusell. Para Ben-Ami (1983: 255-256) la española era comparable con las dictaduras monárquicas que se establecieron en los Balcanes, en Polonia y en Portugal, que a diferencia del fascismo italiano, y aún más del nacionalsocialismo alemán, no pretendieron establecer un control totalitario de la sociedad, aunque no se basaron únicamente en "las bayonetas y los decretos", pues impulsaron una movilización política limitada mediante partidos creados desde el poder. Gómez Navarro (1991: 94-100) la sitúa entre los regímenes que denomina militares-corporativos, cuya diferencia con los regímenes fascistas destaca. Y para Tusell (1995: 611-612) era un régimen autoritario pero no fascista semejante a otros de la Europa central y oriental en los años de entreguerras.

Sin poner en duda esa línea interpretativa, el punto más importante que se desprende de los informes diplomáticos italianos es la persistente tendencia de Primo de Rivera a inspirarse en el modelo fascista, tendencia que culminó en su intento de institucionalizar el régimen en 1929, fracasó y fue retomada por Franco siete años después.

\section{Bibliografía}

ADAGIO, Carlo (2004). Chiesa e nazione in Spagna: la dittatura di Primo de Rivera (19231930). Milano: Unicopoli. 
ÁLVAREZ CHILLIDA, Gonzalo (1996). El fracaso de un proyecto autoritario: el debate constitucional en la Asamblea Nacional de Primo de Rivera. Revista de Estudios Políticos, 93, 359-375.

BEN-AMI, Shlomo (1983). La dictadura de Primo de Rivera. Barcelona: Planeta.

BOYD, Carolyn (1990). La política pretoriana en el reinado de Alfonso XIII. Madrid: Alianza Editorial.

CÁRCEL ORTÍ, Vicente (2007). La nunciatura de Federico Tedeschini en Madrid durante la monarquía (1921-1931). Archivium Historiae Pontificiae, 45, 97-184.

CORTS I BLAY, Ramon (2010). Linforme final de la visita apostólica de 1928 del nunci Tedeschini a Catalunya. Analecta Sacra Tarraconensia, 83, 485-757.

DÍAZ FERNÁNDEZ, Paloma (2005). La dictadura de Primo de Rivera: una oportunidad para la mujer". Espacio, Tiempo y Forma, Serie V, Historia Contemporánea, 17, 175-190. https://doi.org/10.5944/etfv.17.2005.3118

DOMÍNGUEZ MÉNDEZ, Rubén (2013). El fascismo italiano y la Exposición Internacional de Barcelona de 1929. Diacronie: Studi di Storia Contemporanea, 14. https://diacronie.revues.org/256.

GARCÍA QUEIPO DE LLANO, Genoveva (1987). La rebelión de los estudiantes y la movilización intelectual contra la Dictadura (1929). Boletín de la Real Academia de la Historia, CLXXXIV, 315-358.

GARCÍA QUEIPO DE LLANO, Genoveva (1988). Los intelectuales y la dictadura de Primo de Rivera. Madrid: Alianza Editorial.

GÓMEZ NAVARRO, José Luis (1991). El régimen de Primo de Rivera: reyes, dictaduras y dictadores. Madrid: Cátedra.

GONZÁleZ CALBET, María Teresa (1987). La Dictadura de Primo de Rivera: el Directorio Militar. Madrid: El Arquero.

GONZÁLEZ CALLEJA, Eduardo (1999). El máuser y el sufragio: Orden público, subversión y violencia política en la crisis de la Restauración (1917-1931). Madrid: CSIC.

GONZÁlEZ CALLEJA, Eduardo (2007). La Dictadura de Primo de Rivera: ensayo bibliográfico. Bulletin d'Histoire Contemporaine de l'Espagne, 43, 191-254.

LÓPEZ IÑíGUEZ, Julio (2015). Noventa años de historiografía sobre la dictadura de Primo de Rivera: un estado de la cuestión. Historiografías, 10, 85-108.

MARTÍNEZ ÁLVAREZ, Josefina (2015). Un paréntesis 'apacible': las relaciones bilaterales entre España y el Vaticano durante la dictadura de Primo de Rivera. Aportes, 88, 79-114.

MONTES, Pablo (2012). La Dictadura de Primo de Rivera y la historiografía: una confrontación metodológica. Historia Social, 74, 167-184.

MUGNAINI, Marco (1998). Italia, Spagna e la formazione di un nuovo equilibrio mediterraneo, 1923-1928. Spagna Contemporanea, 14, 53-77.

OLÁBARRI GORTÁZAR, Ignacio (1995). Principales interpretaciones de la Dictadura de Primo de Rivera (1923-1930), Hispania, 189, 315-325.

OLÁBARRI GORTÁZAR, Ignacio (1996). Problemas no resueltos en torno al pronunciamiento de Primo de Rivera. Revista de Historia Contemporánea, 7, 223-248. 
PALOMARES, Gustavo (1989). Mussolini y Primo de Rivera: política exterior de dos dictadores. Madrid: Eudema.

QUIROGA FERNÁNDEZ DE SOTO, Alejandro (2005). Perros de paja: las Juventudes de la Unión Patriótica. Ayer, 59, 69-96.

QUIROGA Alejandro (2013). La trampa católica: la Iglesia y la dictadura de Primo de Rivera. En BOTTI, Alfonso; MONTERO, Feliciano; QUIROGA, Alejandro (eds.). Católicos y patriotas: religión y nación en la Europa de entreguerras (162-192). Madrid: Sílex.

RASCA, Ugo (2000). La Spagna e la diplomazia italiana dal 1928 al 1931: dalla revisione dello statuto di Tangeri alla Seconda Repubblica. Alessandria: Edizioni dell'Orso.

REY REGUILLO, Fernando (1987). Ciudadanos honrados y somatenistas: el orden y la subversión en la España de los años veinte. Estudios de Historia Social, 42-43, 97-159.

ROIG ROSICH, Josep M. (1992). La dictadura de Primo de Rivera a Catalunya: un essaig de repressió cultural. Montserrat: Publicacions de l'Abadia de Montserrat.

SECO SERRANO, Carlos (1986). El cerco de la monarquía: la ruptura de los partidos dinásticos con Alfonso XIII durante la dictadura de Primo de Rivera. Boletín de la Real Academia de la Historia, CLXXXIII, 161-269.

SUEIRO SEOANE, Susana (1992a). España en el Mediterráneo: Primo de Rivera y la 'cuestión marroquí, 1923-1930. Madrid: UNED.

SUEIRO SEOANE, Susana (1992b). El complot catalanista de Prat de Molló. Espacio, Tiempo y Forma: Historia Contemporánea, 5, 385-396.

SUEIRO SEOANE, Susana (2005). Le relazioni Spagna-Italia negli anni Venti. En DI FEBO, Giuliana; MORO, Renato (eds.). Fascismo e franchismo.: relazioni, immagini, rappresentazioni (29-44). Roma: Rubbettino.

SUEIRO SEOANE, Susana (2013). La política exterior de la Dictadura de Primo de Rivera en el contexto autoritario de los años 20. En FORNER MUÑOZ, Salvador (coord.). Coyuntura internacional y política española (1898-2004) (65-80). Madrid: Biblioteca Nueva.

TUSELL, Javier (1987). Radiografía de un golpe de Estado: el ascenso al poder del general Primo de Rivera. Madrid: Alianza Editorial.

TUSELL, Javier (1995). La Dictadura de Primo de Rivera. En Historia de España Menéndez Pidal, tomo XXXVIII, vol. II, Madrid: Espasa Calpe.

TUSELL, Javier; SAZ, Ismael (1982). Mussolini y Primo de Rivera: las relaciones políticas y diplomáticas de dos dictaduras mediterráneas. Boletín de la Real Academia de la Historia, CLXXIX, 413-484. 